\title{
Modeling of welfare in the context of socialization
}

\author{
Ivankina Lyubov Ivanovna \\ Department of Economic \\ National Research Tomsk Polytechnic University \\ Tomsk, Russia \\ ivankina@tpu.ru \\ Kozlova Natalia Viktorovna \\ Psychology Department \\ National Research Tomsk State University \\ Tomsk, Russia \\ akme_2003@mail.ru
}

\author{
Berestneva Olga Grigorevna \\ Institute of Cybernetics \\ National Research Tomsk Polytechnic University \\ Tomsk, Russia \\ ogb2004@mail.ru \\ Maklakova Taisiya Glebovna \\ Department of Management \\ National Research Tomsk Polytechnic University \\ Tomsk, Russia \\ mclakova.t@gmail.com
}

\begin{abstract}
The relevance of the theme arised from the searching for an answer to the question about validity of refusal from the idea of general welfare in terms of growing inconsistency rates of change the subsystems of contemporary society. The purpose of the article is implementation of the search for units of genetic information (meanings, ideas, values), involved in the construction of social welfare model. For this purpose, we solved the problems of the comparative analysis devoted social welfare's ideas, which allows to identify the key ideas of model construction. A constructivist approach, methods of hermeneutical analysis, explication and comparative analysis were used in this study. The result of the research is: the units of genetic information of social welfare model in the context of the evolutionary process have been identified; It justified that the modeling of social welfare takes place predominantly at the management level (system level) and addressing the needs (practical level), the correlation of factors affecting the dynamics of the social welfare of the individual and society was examined
\end{abstract}

Key words: sociality, social context, well-being, welfare, social model, social indicator, social justice, life-world, subjective assessment of happiness.

\section{INTRODUCTION}

Social welfare model is directly connected with social ideal, which is one of the valuable society development models, and is set by the notion "social welfare". The relevance of scientific interest to the problem of social welfare is principally determined by the necessity to study the phenomenon nature, which is as follows: when the level of aspiration and living standards increase, the degree of satisfaction and well-being at a subject level decrease. Modern research is more frequently focuses on the necessity to study the correlation of internal and external factors and their interconnection, which influence generation and development of optimum welfare level. The reason for the stated approach is transformation of the notion about the nature of welfare as a social phenomenon. In this regard, distinguishing the aspects of understanding the social welfare nature during its evolution arouses interest for researchers.

Scientific literature presents a considerable number of publications reflecting the opinions of Russian and foreign authors about the notion of welfare nature in its different aspects (economic, social, emotional, financial, spiritual, physical, objective, subjective, etc.), which enables distinguishing the major transformations in understanding welfare sociality in the context of its historicity, specificity.

\section{EMOTIONAL EVALUATION FEELING - THE BASIS OF}

FORMING NOTIONAL COMPONENT OF SOCIAL WELFARE

During the history of human civilization emotional tension has been taken as a basis of notion on welfare. Aristotle was one of the first scientists who began to measure satisfaction and stated the dependence of happiness on welfare, having defined getting happiness as an objective of human being. Up to now, the problem of happiness within the meaning of welfare nature sociality has been a key one [1].

As modern economists state [2], happiness can be seen as an objectively measurable notion. R. Isterlin points, that such notions as "life satisfaction" and "happiness" are used in economic research nowadays as synonyms [3]. Since the development of the concept "perceptible quality of life" in 1970s (works of A. Campbell, F. Converse, B. Rogers, F. Andrews, S. Witney, etc.) this cognitive evaluation category has become the basis of forming objective social indicators.

Happiness, according to B. Frey [4] can be expressed in terms of the following macroeconomic function:

$$
\mathrm{Wit}=\alpha+\beta \mathrm{Xit}+\varepsilon \text { it }
$$

where $\mathrm{X}=\mathrm{x} 1, \mathrm{x} 2, \mathrm{x} 3 \ldots$ are known variables, such as sociodemographic, institutional and economic criteria, environment condition, etc. for a certain individual i during the time interval t.

Each factor, correlating with a subjective evaluation of happiness can be considered separately regardless of the other influencing variables. The role of factors, influencing personal welfare not themselves but by means of their subjective value (assessments) for a person's welfare is played by external welfare as well. "We construct the implications of events, reasons J. Bugental, - on the basis of what we are and what the objects included in this event" are [5]. Implications do not 
belong to the world and its objects and, in equal measure, are not generated inside a personality, while they are generated in a space between a personality and an event due to their interaction and are filled with the features of both sides.

In fact, the number of such factors is not very large. Every person wants to stay healthy, active, able to cope with the arising problems, to have an opportunity to reach own goals. People need support and other people's positive attitude and there are a lot of other things we want to have and what we want to be in our world. In his work "Happiness: the lessons of new history" R. Layard studies the factors encouraging the utmost happiness, defies these factors as "a large seven" of the major factors. He included the following factors to this list: family relations, financial situation, job, society and friends, personal freedom, personal values [2].

Thus, subjectiveness of welfare sociality is a complicated functional system of subject-object relations, where definite values, mindsets, inclinations at the level of a certain individual and society as a whole are integrated.

But how can welfare sustainability be guaranteed and provided? The answer to this question was connected with functioning of social institutions, structuring people's lives and providing fixed starting points (being described in the ideas of social equality, social welfare and the state's responsibility for its provision) for the satisfaction of certain needs.

\section{SOCIAL WELFARE CONTEXT}

Searching the methods, mechanisms and directions of provision and realization of social welfare and understanding social welfare phenomenon nature have been being developed almost concurrently. The beginning of welfare sociality was connected with moral-ethical aspect, having fixed welfare in moral virtues (Plato, Aristotle, John Locke, Th. Hobbes, I. Kant, Jean-Jacques Rousseau, B. Spinoza, S.L. Frank, etc.), identified with the result of coordinated social behavior and effective interaction. Moral virtue is interpreted as an assembly of positive moral personality qualities contributing to getting welfare, and the major condition of social welfare is social order which provides the society progressive development and its components stable functioning. There are two essential origins in a social individual: personal and social, which harmoniously complement each other and frequently come into antagonism, which stipulates finding a scientific answer to the question about the proportion of individual and social welfare.

Following the moral aspect, there was the social aspect of welfare distinguished and began to be extensively worked out in the notion of welfare nature sociality. In this connection, there is a very meaningful definition of social welfare made by E. Durkheim. According to it, social welfare is defined as the best social structure based on a social solidarity, which exists due to general recognition and realization of social factors being the norms, ideas, values developed by a collective consciousness of people [6].

Social effect is demonstrated in creating positive socium environment and the optimality of a person's living space organization is characterized by welfare at the level of state as a whole and presents its objective side. The parameters, fixing

The research was conducted in Tomsk Polytechnic University with financial support from Ministry of Education and Science of the Russian Federation in line with accomplishing the research scientific work on "Evaluation and improvement of social, economic and emotional welfare of elderly people”, contract № 14.Z50.31.0029. the model of social welfare at the institutional level are functionality of vitality as a combination of physical, psychological, cultural, productive-economic, socio-political, socio-ecological subjectness and optimality of living space organization, which is defined by the level of development and quality of functioning of social institutions and organizations aimed at providing public access to vital welfare, contribute to rights, interests, and needs enforcement, generate, develop and restore vitality.

Satisfaction of needs and obtainment of welfare is implemented in a certain space-time continuum and the possibility and availability of possessing welfare as a resources structural element get under the effect of external factors such as providing life resources for satisfying basic human needs, normalization of relations between people, etc. and, on the other hand, due to inner factors represented by actions taken at the individual level, subject feeling, evaluating the welfare level on the basis of inner self-awareness of a certain individual, etc.

Conspicuously, welfare sociality once again demonstrates the connection of the objective and the subjective, meaningfulness and value of life as a whole as the means of achieving personal aims [7], E. Diener with coauthors [8], on the one hand and, waiting for what it is required to strive for, on the other hand. The given aspect is fixed by the notion "level of life" comprising a great number of amenities (by means of using these amenities a certain level of existence is achieved), and the possibility of obtaining the amenities is provided by finding genetic relation with the concept of justice in this part.

The range of ideas about getting welfare through human activity in various spheres of life realizes the adaptive welfare function, which is directly connected with the necessity to choose actions as the security of obtaining the expected result (i.e. welfare in our case) in different situations. Thanks to systematicity and involvement in wide nets of social interaction, analysis of own positive actions results a person evaluates their life as a more satisfactory one.

What do we wish other people if we wish well-being? Definitely we wish a person to have welfare. The choice of welfare is the process of referring something an individual wants to what he or she really needs and appreciates, while welfare is an attractive image of what people want to obtain. Such a wide welfare context forms a similar wide range of its types ranging from material object, products, things, to diverse feelings. Therefore, the process of getting welfare is rather stable, firm and permanent in its principle basis, and, simultaneously, variable on the part of the desired things diversity.

Hermeneutical approach, which refers social welfare to material substratum, can be applied for analyzing welfare sociality. For a person who satisfies own needs, welfare can be gained through the systematic consumption of the objective material and social world items (clothing, groceries, acces sories, etc.).

Factors, influencing the social welfare of an individual and society as a whole, its changes, are arranged according to the 
hierarchy of needs, given by A. Mas low and called "a pyramid of needs." The degree of individual dependence on the society is defined by the pyramid layers. Beginning from the lowest layers and during getting higher, to the layer of the highest spiritual requirements, an individual gains a greater dependence on self-ideology, set of senses and values. At this level, there is the possibility of showing gratuitousness, a situation when an individual does not need people to accept his or her ideas, world outlook, convey gratitude for the services rendered, etc, while dedication, desire to fulfill oneself, achieve goals using own resources compensates the lack of other people's interference. A. Maslow paid attention to the necessity of learning to appreciate the supreme greater than the lowest and, "due to the personal enhanced responsibility for the own life and sound set of values, controlling the choices made, people would extensively change the society they live in" [9].

Needs' flow continuity provides social welfare, whose level is dynamic and fluctuates upwards or downwards from the achieved level. Moreover, the consumption flow affects the value system of an individual's provision with material benefits, the degree of person's devotion and dependence on them. People's potential capitalization and tendency to gravitate towards the material benefits as one of the basic needs is complemented (at the conscious level of social regulating) with the tendency to establish tough requirements for people's behavior, one of which is the need of spiritual inner perfection.

The law of needs growth raises the degree of aspiration at the level of an individual and a group and constantly pulls off the welfare boundaries having those notions of welfare that are certainly attainable and possible for the given society at a certain historical period, along with the common ones.

Aristotle began to connect the institutional level providing and guaranteeing welfare obtainment with the state social institution, which must have an objective to make people's welfare a policy strategic aim (similar ideas were developed by Th. Hobbes, John Locke, N. Machiavelli, etc.). The given aspect of welfare sociality notion integrates the efficiency of society social sphere functioning at the state level and the possibility and real configuration of people's social welfare.

Social fairness, social equity and providing social guarantees (J. Kreft, I. Milec, etc.) and later collective guarantees of social support and the arrangement of marketoriented economy are the major principles of social state.

Thus, social fairness does not have a "finite" point being one of the basic factors of social relations stabilization. And it is possible to define society livability with regard to the state of social relations stabilization while the result of social welfare corresponds with the resources vital for an individual development and whose efficiency in the life of every person and a society as a whole is fixed and measured by the system of axiological affirmations, ideas, rules, values, fixing the context of a person's welfare as well as interpersonal context as an actual provision with resources necessary for the living, among which there is the guarantee of safety in the aspect of fairness.

\section{WELFARE MEASUREMENT MODEL}

Welfare phenomenon is aligned with human needs and their fulfillment, self-evaluation of the personal resources of economic achievements and claims, which are mediated by the human value system and purposes, with the individual welfare standards accepted by this person and his or her selfevaluation as of an economic and social agent. Studying welfare aspects implies developing the complex model, which enables to map the dynamics of the living standard and its individual components.

The main notion of developing the modeling methodological approach, which will allow performing simultaneous, mutually reinforcing and consistent analysis of the objective and subjective factors and expert evaluations, is the notion of using the definition of model as a structural description of the test object and such concepts as "model and object adequacy" and "model and object identity" with the purpose of setting the tasks of complex modeling. The stated logic can be applicable to any model types: structural and functional, mathematic, institutional, etc.

Welfare model can be represented by the following interrelated and interdependent system elements: routine practice (micro-level), support institution (meso-level) and security institution (macro-level). Micro-level studies the motives and needs of a certain individual or a micro group. Meso-level is the level of studying a homogeneous group of individuals, a community and an area (a region, a city, etc.). Macro-level is a national and cross-country level of research.

Social welfare is, simultaneously, an objective and subjective phenomenon determined by the routine living environment, in which people meet their needs, implement their projects of life and fulfill their social expectations. The efficiency of living space organization is defined by the level of development and by the quality of social institutions and organizations functioning to ensure the guarantee of universal access to vital goods, assistance in realizing the citizens' rights, interests and needs, as well as the formation and development of life forces and recreation. The government acts as an active participant establishing the "rules of the game" for all the other parties.

The world of a human's routine practices includes the responses to everyday routine enabling to structure social reality basing this process on the frame of differences in people's preferences. Addressing the routine practices allows detecting which individual's needs require to be satisfied, what these needs are, and what institutional forms of satisfying them are. In routine practices human welfare acts as a mechanism of regulating the socially important processes influencing a person's real-life situations and living environments. The major form of everyday living is the practical effect constituting a dynamic unity with the structural context.

The majority of the existing tools for the welfare evaluation are based on using either objective or subjective factors. The combined use of objective and subjective factors enables obtaining a new evaluation quality impossible to get when studying individually. The source of 
activity and development in a complex model is transferred to cross-system interactions. The connections specificity is determined by the content of emotional and evaluating foundations, which give a differently directed tone to the subject activity. The degree of needs fulfillment, stability of social background and life satisfaction is defined by the given components connection and combination.

The sources of information for filling the marked model levels are statistics data, examination results of large population samples according to the general principle as well as certain age groups, regions and territories both within a specific country and the cross-country scale for making corresponding comparis ons.

At the highest, methodological generalization level, welfare as a phenomenon is represented by two processes: individual person's life and the process of social and economic development which this person participates in. What is more, at the stage of adolescence the process of social and economic development is accumulative for the further life and activities. At a mature age a person generates more weal for the social and economic system than he or she consumes. In old age a person is rather a consumer of the social and economic weal than a generator. The given model of the methodological level allows enunciating the challenges for social and economic system in the light of such problem as aging. One of the major challenges is, for example, the necessity to involve the older generation into the productive labor to the greatest possible extent, and, consequently, the government faces the issue of providing employment for the older generation representatives, their training and retraining, developing the appropriate infrastructure and other aspects.

The method of creating the hierarchy of the functions related to the management levels, life support and, actually, the lives of different groups of people is used in developing the structural and functional model of the system-level model of the phenomenon under research. Such approach enables using several targeted restrictions during studying and creating a model modification depending on the goals set [10]. The invariable model part is represented by the control and security functions. The choice of the systemlevel model elements was made on the basis of state authorities both federal and regional, which is reflected in the indicators of the government statistics in the process of forming the corresponding departmental and interdepartmental statistics.

The changeable model part is a social group itself or the object of research throughout the whole variety of individual characteristics, problems, needs and necessities. Elements can be marked according to the following: position in the social and economic system with regard to participating in the process of production (employed/unemployed), social differentiation according to the wage rates (high, middle, low income), etc.

When working out the indicators, it is necessary to take into account the fact that meeting the needs and obtaining weal happens in a definite time-space continuum, is connected with the availability of the weal to be a resources structural element, which is influenced by external factors, being the provision of recourses for the human basic needs satisfaction, normalization of relations between people, as well as internal factors such as subjective experience evaluating the level of needs in a certain weal object.

The most sensible indicators obtaining a larger resolving capability are chosen from the group of indicators characterizing the test object. When working out the living standard indicators, there are the objective (factual) data and subjective experience taken into account. Living standard objective indicators are connected with the facts capable of being identified because they obtain the features of a certain group.

Subjective indicators reflect emotional contentment and record the opinion in the evaluation of a person's inner state (health condition, social optimism, basic values), satisfaction with living conditions (evaluation of family well-being, personal material well-being, as well as evaluation of the satisfaction with living conditions, position in society, personal perspectives), evaluation of external conditions (how effective the social protection authorities, etc. are, how far local authorities are trusted, how favorable the social climate in the place of residence is), evaluation of emotional experience (the anxiety level, sense of isolation, happiness).

In general, the welfare model reflects the structural and functional system of relations. This system integrates specific values, attitudes, intentions, a general program of instrumental and conceptual security and implementation of one or another's attitude in particular behavioral and environmental conditions.

\section{CONCLUSION}

The process of the opinions about welfare sociality evolving is fixed in two equivalent research tendencies. On the one hand, social welfare is considered as a fact and a factor of conceptual certainty in different spheres of a person's and society lives, being fixed in emotionally evaluating experience. On the other hand, the factors of social welfare are various socio-economic determinants motivating and stabilizing welfare at the level of the institutions of social assistance and support, which brings the problem of welfare at the out-and transpersonal level.

Social welfare model has been being formed, by being transformed in the notion of ideal welfare and the methods of its obtainment, under the influence of two key aspects: primarily, searching the answer to existential question: what is the point in people's existence, what are they born for, what should their lives be like? And the second major component is - how can we achieve welfare for the whole society and a certain individual, how can an individual be connected to other people, how is it possible to coexist and stay oneself? 


\section{REFERENCES}

[1] M. Ardyle. Psychology of happiness. Moscow: Progress, 1990, PP. 336

[2] R. Layard. Happiness: lessons of new science. Moscow: Publishing house of the Gaidar Institute, 2012, PP. 389

[3] R. Easterlin. Economics of Happiness. Daedalus, 2004, Vol. 133. P. 26-33.

[4] Money doesn't buy happiness: scientists made unexpected conclusions about the happiness factors (2013). Newsme, from http://newsme.com.ua/business/1857876/ (access date: 29.12. 2014).

[5] J. Bugental. The art of Psychotherapist. Dialogues between a therapist and a patient in humanistic therapy. Moscow: Independent firm «Class», 1998, PP. 336

[6] E. Durkheim. Value and "realistic" judgements. Sociology. Its notion, methods and mission. Moscow: Canon, 1995, PP. 352

[7] P.P. Fesenko. What is psychological welfare? Brief overview of the major concepts. Scientific work of Ph.D. candidates and doctoral candidate. Moscow: Publishing house of Moscow University of the Humanities, 2005, T.46. PP. 35-48

[8] S. Lyubomirsky, L. King, E. Diener. The Benefits of Frequent Positive Affect: Does Happiness Lead to Success?. Psychological Bulletin, 2005, Vol. 131. № 6 P. 803-855.

[9] A. Maslow. New Frontiers of Human Nature. Moscow: Sense, 1999, PP. 425.

[10] Monastyirnyiy I.A., Ivankina L.I., Gumennikov I.V., Pavlova I.A. Complex modeling of complicated social and economic, psychological and physiological phenomena in terms of studying elderly people welfare // Procedia Technology Transfer: a new dimension. IX International Forum "From Science to Business", 2022.05.2015 - St. Petersburg., Publishing house "Icing", 2015 - pp.127-129 
